\title{
Joachim Périon, Dialogues. De l'origine du français et de sa parenté avec le grec
}

\section{Michele Mastroianni}

\section{Q OpenEdition}

1 Journals

\section{Edizione digitale}

URL: https://journals.openedition.org/studifrancesi/40477

DOI: 10.4000/studifrancesi.40477

ISSN: 2421-5856

\section{Editore}

Rosenberg \& Sellier

\section{Edizione cartacea}

Data di pubblicazione: 1 juillet 2004

Paginazione: 172-173

ISSN: 0039-2944

\section{Notizia bibliografica digitale}

Michele Mastroianni, «Joachim Périon, Dialogues. De l'origine du français et de sa parenté avec le grec», Studi Francesi [Online], 142 (XLVIII | I) | 2004, online dal 30 novembre 2015, consultato il 09 septembre 2021. URL: http://journals.openedition.org/studifrancesi/40477 ; DOI: https://doi.org/10.4000/ studifrancesi. 40477

Questo documento è stato generato automaticamente il 9 septembre 2021.

\section{(c)}

Studi Francesi è distribuita con Licenza Creative Commons Attribuzione - Non commerciale - Non opere derivate 4.0 Internazionale. 


\title{
Joachim Périon, Dialogues. De l'origine du français et de sa parenté avec le grec
}

\author{
Michele Mastroianni
}

\section{NOTIZIA}

JOACHIM PÉRION, Dialogues. De l'origine du français et de sa parenté avec le grec, texte présenté, établi, traduit et annoté par Geneviève DEMERSON et Alberte JACQUETIN, Paris, Champion, 2003, pp. 827.

1 I due editori offrono una riproduzione anastatica dei Dialogorum de linguae Gallicae origine, eiusque cum Graeca cognatione, libri quatuor di Joachim Périon (dell'unica edizione: Paris, chez Sébastien Nivelle, 1555), accompagnandola con una traduzione in francese riccamente annotata. Il benedettino Joachim Périon (1499-1559) è noto soprattutto per le sue traduzioni in latino e i suoi commenti di Aristotele, e per le polemiche in difesa del filosofo greco, in particolare quella condotta con asprezza con Pierre de La Ramée. Ma in un'opera peraltro di vasti interessi eruditi - storico antiquari e anche letterari occupano un posto di rilievo i quattro libri dei Dialogi sull'origine della lingua francese, in cui opponendosi al mito correntemente accettato di una derivazione del francese dall'ebraico, lingua madre, Périon, riprendendo suggerimenti dell'ammiratissimo Budé e rispondendo all'ambizione nazionalistica di Francesco I, largamente condivisa in Francia, di vedere collegata la lingua patria alla dignità del greco, sostiene e illustra una parentela della langue gauloise con la più prestigiosa delle due lingue classiche. Nel primo libro l'autore presenta una storia delle lingue umane, che inizia a Babele, tenta di ricostituire le modalità della successiva dispersione linguistica, inserisce i re della Gallia in questo excursus, indicando come questi principi abbiano introdotto il greco tra i loro sudditi. Nel secondo libro vengono illustrate le modalità con cui le inflenze romane e barbare hanno offuscato la percezione di questa parentela. Périon analizza l'evoluzione dei diversi fonemi nel passaggio dalle parole greche al francese, offrendo una serie di esempi ritenuti determinanti. Nel terzo libro e nell'ultima parte del quarto vengono spiegate la nascita e l'origine di parole francesi particolarmente difficili e 
oscure, sulla falsariga del Cratilo di Platone. La restante parte del quarto libro s'interessa soprattutto al sistema degli accenti, a quello del dittonghi e alle grafie corrette. Inoltre riflette sul sistema verbale greco in rapporto a quello francese e parla della classificazione dei verbi greci che, secondo Périon, potrebbe ispirare quella dei verbi francesi. La fine del quarto libro è consacrata a una rapidissima rassegna delle altre parti del discorso. L'introduzione (pp. 15-60) delle due studiose editrici offre non solo tutti i dati reperibili su Périon, ma analizza con cura i Dialogi ricostruendone le tesi e contestualizzandole storicamente, e soprattutto illustrando i procedimenti dell'erudito rinascimentale arreca un apporto significativo allo studio delle linguistica cinquecentesca. Anche le note accurate fomiscono uno strumento di ricerca utilissimo. Ricchi gli indici. 